\title{
Intervenções Psicossociais no Sistema Carcerário Feminino
}

Psychosocial interventions in the female prison system

Marcela

Ataide Guedes
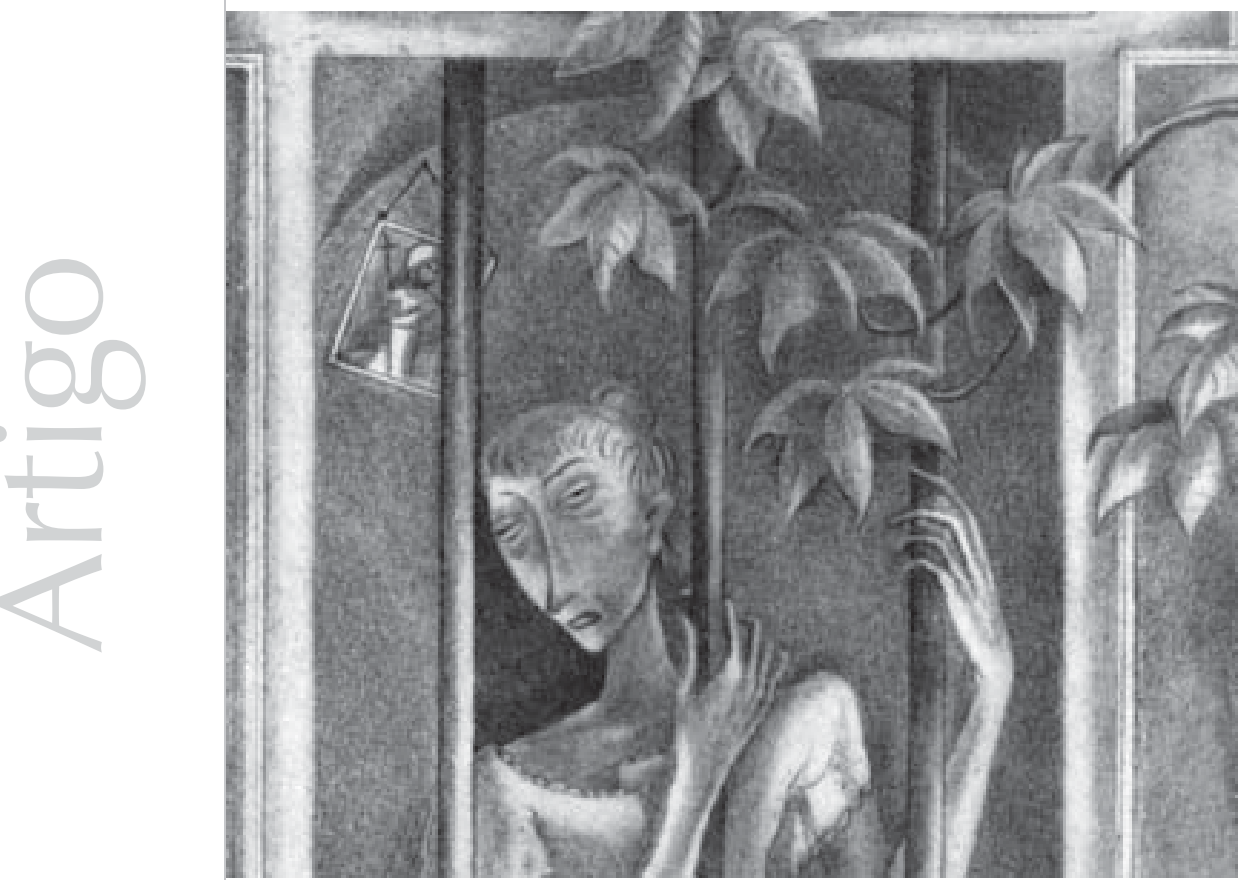


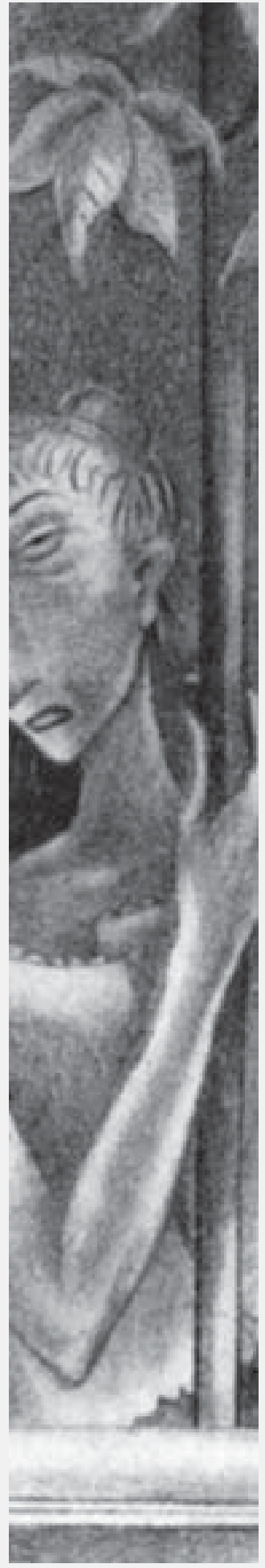

Resumo: Um dos meios de percepção do crescimento da violência na sociedade atual pode ser mensurado pelo aumento da população carcerária, o que pode favorecer a violação dos direitos humanos. Considerando os poucos dados disponíveis, o presente trabalho buscou investigar essa população, visando a contribuir para a produção de conhecimento sobre esse grupo. Por meio do plantão psicológico, realizado numa delegacia de Belo Horizonte/MG, acolhemos demandas espontâneas de sessenta e sete mulheres, de agosto de 2004 a julho de 2005. A faixa etária das mulheres variou de dezoito a quarenta e dois anos, e o tempo de prisão, de um a trinta e seis meses. A análise temática dos assuntos abordados pelas mulheres aprisionadas salientou características como o cotidiano prisional, a maternidade/relações familiares, as vivências amorosas internas/externas e as relações de gênero. Foram apontadas estratégias individuais e coletivas que visam a facilitar a dinâmica interna cotidiana: o apego aos filhos/familiares, as práticas religiosas, as oficinas de artesanato, o trabalho na limpeza e as relações amorosas internas.

Palavras- chave: sistema prisional feminino, exclusão social, Psicologia social.

Abstract: One of the means of perception of the increase of violence in the current society can be measured by the growth of the incarcerated population, what possibly contributes to the breaking of human rights. Singularities have already been observed in relation to female inmates, what makes the matter still more difficult to be faced due to few available data. The present study aimed to investigate this population in order to contribute to the knowledge about this group. Through the psychological shift in a police station in Belo Horizonte we received spontaneous statements from 67 women from August 2004 to July 2005. The women's age ranged from 18 to 42 and the sentence length from 1 to 36 months. An analysis of the themes for the issues brought by the inmates showed characteristics such as everyday life in prison, maternity/family relationships, internal and external love relationships and gender relationships. Individual and group strategies were listed to facilitate the everyday internal dynamic: family / parental attachment, religious practice, handicraft workshops, cleaning work and inmates' love relationships.

Keys word: female prison system, social exclusion, Social Psychology. 
"(...) o que os dados mostramé que a prisão, tanto pela privação de liberdade quanto pelos abusos que ocorrem em seu interior, parece ser apenas mais um elo na cadeia de múltiplas violências que conformam a trajetória de uma parte da população feminina.

1 CENEX/UFMG

2 Professora do Departamento de Psicologia/FAFICH/ UFMG.

30 presente tra-balho também orien-tado pela Profa Dra Ingrid Faria Gianordoli-Nascimento (Dep.de Psicologia) FAFICH/UFMG), contou com a colaboração do psicólogo Alessandro Vinícius de Paula (mestrando do Programa de Pós-graduação em Psicologia/FAFICH/ UFMG), que participou ativamente das atividades de coorientação e intervenção.
O presente trabalho baseia-se em um projeto que integrou atividades de ensino, pesquisa e extensão.

Teve início em agosto de 2004, como atividade de pesquisa e intervenção, através da aproximação com o sistema prisional de Belo Horizonte/MG, que nos apresentou uma realidade que demandava e permitia o desenvolvimento de um projeto de extensão que incluiu uma intervenção terapêutica através do atendimento de plantão psicológico, orientado e supervisionado pela Profa $\mathrm{D}$ D $\underline{a}$ Ingrid Faria Gianordoli-Nascimento. ${ }^{2}$

Tal demanda surge de uma delegacia situada na Capital mineira, que solicitou nossa participação junto a um projeto que buscava contribuir para o processo de inclusão, recuperação e construção de cidadania das mulheres que se encontram detidas, através do trabalho em atividades internas e cursos de trabalhos manuais, o que permitiu uma profissionalização, já que visava à reinserção social e no mercado de trabalho.

A articulação entre a vivência do plantão psicológico e a revisão da literatura nos permitiu descrever algumas das particularidades da realidade institucional e da vida dessas mulheres, que se revelaram informações fundamentais para a compreensão deste trabalho ${ }^{3}$.

É consenso entre especialistas, opinião pública e o próprio governo que o sistema penitenciário do País vive uma crise aguda, seja pelas péssimas condições de vida nos presídios e carceragens, seja em decorrência dos casos de corrupção que envolvem policiais, funcionários e juízes e que aparecem freqüentemente nos jornais.

No que tange à carceragem feminina, Soares e Ilgenfritz (2002) apontam:

“(...) o que os dados mostram é que a prisão, tanto pela privação de liberdade quanto pelos abusos que ocorrem em seu interior, parece ser apenas mais um elo na cadeia de múltiplas violências que conformam a trajetória de uma parte da população feminina. Na melhor das hipóteses, ela não favorece em nada a interrupção da violência e da criminalidade. $\mathrm{Na}$ pior, ela reforça e contribui para que a violência se consolide como a linguagem predominante na vida das presas e daqueles que as cercam. O ciclo da violência, que se inicia na família e nas instituições para crianças e adolescentes, perpetua-se no casamento, desdobra-se na ação tradicional das polícias e se completa na penitenciária, para recomeçar, provavelmente, na vida das futuras egressas" (p. 126).

A partir do exposto, um aspecto fundamental a ser ressaltado diz respeito ao contexto de violência que muitas dessas mulheres vivenciaram e continuam a vivenciar, que inclui, além das agressões físicas, sexuais e psicológicas diretamente sofridas ao longo da existência, perdas violentas de parentes próximos e/ou de parceiros conjugais.

Destacamos ainda outras especificidades do cárcere feminino. Assis e Constantino (2001) descrevem que existe um imaginário social construído em torno da criminalidade feminina, que é acolhido inclusive por autoridades como juízes, delegados, carcereiros, advogados, etc. Concebe-se que as mulheres são fortemente influenciadas por estados fisiológicos e que seus crimes são, em grande escala, cometidos no espaço privado, já que o espaço público ainda Ihes é muito negado. Muitas vezes se envolvem em crimes passionais ou naqueles cometidos sob violenta emoção. Quando cometem crimes de outra natureza, como a participação no tráfico de drogas, esses estão vinculados a uma posição subalterna justificada como uma extensão natural de suas relações afetivas. Acredita-se que participem dos delitos em número menor que os homens e sejam postas à margem das atividades importantes. São consideradas perigosas e não confiáveis, capazes de traição, com exceção das que 
passam por provas especiais de valor. Exceção se faz somente quando se trata de lésbicas ou prostitutas, que são identificadas como mais parecidas com os homens, mais machonas e mais habituadas à rua e à delinqüência.

No que tange ao estudo desse fenômeno, concordamos com Frinhani (2004), que enfatiza o excesso de tematização por programas televisivos que tratam de assuntos como violência, direitos humanos e criminalidade, o que possibilita a construção de um imaginário, muitas vezes de forma preconceituosa e estigmatizante, dessas questões.

Dessa forma, a mídia acaba por contribuir, de forma maciça, para a manutenção de uma ideologia opressora e comprometida com os interesses da classe dominante. Assim, a pequena importância dada à criminalidade feminina se deve, entre outros fatores, à falta de dados objetivos, que responde pelo desinteresse em aprofundar a discussão através de uma investigação científica rigorosa.

Este trabalho pretende oferecer a possibilidade de se empreender um estudo sobre a vida de mulheres encarceradas, a partir do que elas pensam, agem e falam de forma sistematizada, o que permite, além de compreender aspectos relevantes a esse respeito, compreender também as relações estabelecidas com suas diferentes redes de relacionamento social, incluindo o ambiente prisional, com o objetivo de elaborar políticas públicas.

Através do plantão psicológico, visamos a fornecer um espaço de atenção psicossocial à saúde dessas mulheres, buscando contribuir para a produção de conhecimentos específicos sobre essa realidade tão pouco estudada até o momento.

Sendo assim, Menandro (1998) menciona dois pontos chave no processo de valorização do indivíduo como ator social e que têm implicações metodológicas em nosso trabalho: a relevância de se ouvir as explicações do sujeito, não restringindo a análise à observação da ação, e a valorização de quaisquer informações que possam ser extraídas das ações ou de produtos das ações dos indivíduos. Percebe-se, dessa forma, a importância recentemente dada pelas ciências sociais à vida cotidiana e a sua aplicabilidade nesta experiência em particular.

\section{Procedimentos metodológicos}

O atendimento na modalidade plantão psicológico visa ao atendimento individual e de emergência às presas alocadas na instituição, e tem como objetivos acolher suas demandas emocionais e contribuir para fornecer atenção psicossocial à saúde dessas mulheres. Por ser mais conveniente à dinâmica do estabelecimento, o plantão psicológico ocorreu regularmente, no turno da manhã, cinco vezes por semana, e foram atendidas, em média, três mulheres por turno.

Antes de começar cada atendimento, explicouse detalhadamente às detentas quais eram os objetivos do mesmo, com garantia de anonimato e sigilo. Todos os atendimentos foram individuais, com duração média de cinqüenta minutos, e realizados em espaço privado, sem a presença de outras detentas ou membros do DI (agentes penitenciários e/ ou policiais).

$\mathrm{O}$ atendimento foi baseado numa proposta teórico-metodológica desenvolvida pelo aconselhamento psicológico, que propõe um processo de integração transdisciplinar em suas bases teórico-conceituais, visando a promover uma intervenção psicossocial.

Os atendimentos foram discutidos em supervisão semanal e possibilitaram a construção de um banco de dados que continha os relatos clínicos dos atendimentos e das intervenções específicas necessárias a cada caso. 
Para o desenvolvimento do plantão psicológico, tomaram-se como base as propostas de Mahfoud (1987) e Barbanti \& Chalom (1999), buscando proporcionar um espaço de acolhimento de demandas diversas que se manteve à disposição de quaisquer detentas que dele necessitassem, sendo que a mesma detenta podia ser atendida por diferentes estagiários, caso necessário.

Segundo Mahfoud (1987), "esse sistema pede uma disponibilidade para se defrontar com o não planejado e com a possibilidade de que o encontro seja único" (p. 75). Em nosso caso específico, podemos dizer, a partir dos dados

"(...) aceitar manter-se centrado na vivência da problemática que emerge com sua ansiedade e força particulares no próprio momento de pedido de ajuda, acompanhando a variação da percepção de sie das circunstâncias pela direção que a clarificação a levar"

Mahfoud coletados, que, em 50\% dos casos, houve retornos, mas em nenhum deles se configurou um processo de psicoterapia, já que nosso objetivo primordial foi estar disponível para o maior número de demandas possível.

Mahfoud (1987), ao descrever o trabalho do conselheiro-psicólogo, indica a importância de uma posição de abertura que facilite ao sujeito uma visão mais clara de si mesmo e daquilo que vivencia para gerar um pedido de ajuda. Nesse sentido, as perguntas devem estar sintonizadas com a fala do sujeito, o que implica uma escuta atenta e uma disponibilidade e entrega por parte do conselheiro e facilita o processo de apropriação, pelo sujeito, de suas demandas e questões:

“(...) aceitar manter-se centrado na vivência da problemática que emerge com sua ansiedade e força particulares no próprio momento de pedido de ajuda, acompanhando a variação da percepção de si e das circunstâncias pela direção que a clarificação a levar" (Mahfoud, 1987, p. 83).

Na análise do material obtido nas entrevistas, optamos por uma abordagem qualitativa. Em função disso, ouvir as mulheres encarceradas e observar o seu cotidiano prisional mostrouse fundamental, já que, segundo Becker (1994), há um valor nas "interpretações que as pessoas fazem da sua própria experiência como explicação para o comportamento. Para entender porque alguém tem o comportamento que tem, é preciso compreender como lhe parecia tal comportamento" (p. 103).

Perceber os sujeitos como construtores da sua história é permitir que eles compreendam os fenômenos que os cercam à sua maneira, é abrir espaço para que também se percebam como sujeitos sociohistóricos ativos desse processo. Minayo (1999) sublinha a relevância da carga histórica que possui a pesquisa psicossocial, uma vez que evidencia a realidade e a dinâmica social, os interesses de classe e de determinados grupos intra e extrainstitucionalmente.

Deve-se ressaltar que, em alguns momentos, foi necessário cautela devido ao risco de os interlocutores (entrevistados) contarem sua história acreditando que o entrevistador poderia ser levado a influenciar as autoridades das quais seu destino depende. Alguns profissionais são esperados pelas detentas por serem pessoas estranhas à instituição (o que significa uma isenção e possibilidade de confiança) e por indicarem uma possibilidade de revisão do processo.

\section{Resultados e discussão}

Durante o desenvolvimento do plantão psicológico (agosto de 2004 a julho de 2005), foram atendidas sessenta e sete mulheres, com índice de retorno regular ao atendimento de $50 \%$. A mulheres possuíam idades que variavam de dezoito a quarenta e dois anos, com tempo de permanência na delegacia que variava de um mês a três anos. O nível de escolaridade, representado na Tabela 1 , concentrou-se no segmento ensino fundamental incompleto (45,7\%), seguido pelo ensino médio (completo e incompleto) e analfabetismo (14,3\% cada), e, por fim, ensino fundamental completo $(11,4 \%)$. 
Tabela 1: Nível de escolaridade das mulheres atendidas

\begin{tabular}{|l|c|}
\hline Nível de escolaridade & $\%$ \\
\hline Analfabetismo & $14,3 \%$ \\
\hline Ensino fundamental - incompleto & $45,7 \%$ \\
\hline Ensino fundamental - completo & $11,4 \%$ \\
\hline Ensino médio - incompleto & $14,3 \%$ \\
\hline Ensino Médio - completo & $14,3 \%$ \\
\hline
\end{tabular}

Soares \& Ilgenfritz (2002), em um estudo em presídio do Rio de Janeiro, também verificaram, entre as mulheres encarceradas, o baixo grau de escolaridade, o que normalmente é associado a baixas condições socioeconômicas. Tais dados requerem cuidado em sua análise, uma vez que não se pode afirmar haver uma relação direta entre baixa escolaridade e condição socioeconômica com índices de criminalidade. Segundo Velho (2000), essa freqüente e equivocada relação tende a reforçar o estigma imposto às populações pobres, tidas como perigosas e violentas.

Os sujeitos pertencentes às classes de baixa renda tendem a sofrer maior ação da Justiça através do aparato judiciário policial. Assim, as prisões ficam cheias de pobres e se reproduz um estereótipo de criminoso como aquele proveniente de bolsões de pobreza, não sendo a população carcerária uma amostra fidedigna do conjunto total de infratores (Zaluar, 2000).

No que se refere ao estado civil, os dados estão sistematizados conforme a autodeclaração das mulheres, não havendo relação direta com o estado civil oficial. $30 \%$ declararam-se casadas/amigadas; $25,3 \%$ das mulheres declararam-se solteiras; $7,5 \%$, separadas/desquitadas/ divorciadas, e $3,0 \%$, viúvas, conforme Tabela 2.
Tabela 2: Estado civil autodeclarado pelas mulheres

\begin{tabular}{l|c}
\hline Estado civil & $\%$ \\
\hline Viúva & $3,0 \%$ \\
\hline Separada, desquitada, divorciada & $7,5 \%$ \\
\hline Solteira (não envolvida em relação & $25,3 \%$ \\
\hline conjugal ao ser presa) & $30,0 \%$ \\
\hline Casada/amigada & $34,2 \%$ \\
\hline Não respondeu &
\end{tabular}

Percebemos que há uma aparente relação entre relacionamento conjugal e tipo de crime cometido. As mulheres casadas/amigadas e as separadas/desquitadas/divorciadas declaram, na maioria das vezes, que foram presas em função do relacionamento com seus companheiros seja por meio do tráfico ou da violência doméstica. As solteiras estão, em geral, detidas por uso/tráfico de drogas e crimes contra o patrimônio.

Constatou-se que $87,8 \%$ das mulheres eram mães, e $12,2 \%$ não tinham filhos. Das mulheres-mães, $37,2 \%$ tinham dois filhos; $34,9 \%$, apenas um; $16,3 \%$, quatro ou mais filhos, e $11,6 \%$, três filhos, conforme apresentado na Tabela 3.

Tabela 3: Número de filhos das mulheres atendidas

\begin{tabular}{l|c|}
\hline Número de filhos & $\%$ \\
\hline Um filho & $34,9 \%$ \\
\hline Dois filhos & $37,2 \%$ \\
\hline Três filhos & $11,6 \%$ \\
\hline Quatro ou mais filhos & $16,3 \%$ \\
\hline
\end{tabular}

A relação entre a entrada no crime e a maternidade foi constatada nos relatos das mulheres atendidas. Na sua maioria, alegavam uma relação entre os delitos cometidos e a tentativa de assegurar aos filhos acesso ao conforto e aos bens de consumo divulgados na mídia. A Tabela 4 indica os responsáveis pelo cuidado e guarda dos filhos dessas mulheres após seu aprisionamento. $61 \%$ das 
crianças estão sob a responsabilidade dos avós; $24 \%$ estão sob os cuidados de outros familiares, vizinhos e conhecidos, e 15\% permanecem com o pai. Ressalta-se que muitos pais também se encontram presos, ou as mulheres não sabem de seu paradeiro, por estarem foragidos, o que, de certa maneira, explica a baixa incidência de permanência das crianças com seus progenitores.

Tabela 4: Cuidadores dos filhos das mulheres aprisionadas

\begin{tabular}{l|c}
\hline Cuidadores & $\%$ \\
\hline Os avós & $61,0 \%$ \\
\hline $\begin{array}{l}\text { Outros familiares, vizinhos, } \\
\text { conhecidos }\end{array}$ & $24,0 \%$ \\
\hline O pai & $15,0 \%$ \\
\hline
\end{tabular}

Uma das maiores preocupações apresentadas pelas mulheres é a ausência de contato com os filhos, principalmente aquelas cujos filhos estão com parentes ou vizinhos, o que faz com que tenham poucas informações e visitas das crianças. Isso acarreta um sentimento de medo e culpa por terem "abandonado" os filhos em condições que fogem ao seu controle ou por eles poderem vir a sofrer maus tratos. Descrevem também o receio da perda do vínculo materno, perda da guarda legal, privação material e alimentar, acompanhamento escolar e cuidados com a saúde. Destacamos ainda que essas mulheres se declaram "mães de família" que cumprem o seu papel social, motivo pelo qual não poderiam estar presas.

Trindade (1998; 1999) indica que as mulheres são defensoras de um modelo de maternidade inventada pelos homens, no qual são tanto opressoras quanto oprimidas. Nesse modelo de maternidade, construído a partir do conceito de "instinto materno", as mulheres se sentem responsáveis pela total assistência aos filhos, o que inclui cuidados com a saúde física, emocional e moral das crianças, além de atenção ao processo educacional das mesmas. Em se tratando das mulheres aprisionadas, o que se observa é que, se, por um lado, se sentem culpadas pelo não cumprimento dessas exigências, por outro, acreditam se tornarem passíveis de um tratamento diferenciado pelo aparato judicial, merecendo inclusive "serem absolvidas" quando presas por serem "mães de família", principalmente quando seus delitos estão relacionados com o sustento da casa e das "necessidades" dos filhos.

A análise temática das questões abordadas espontaneamente pelas mulheres referiu-se principalmente a três categorias: cotidiano prisional, maternidade e relações familiares, vivências amorosas e relações de gênero.

\section{Cotidiano prisional}

O desrespeito aos direitos humanos, encontrado em muitas instituições penais, evidencia a múltipla penalização imposta aos criminosos. Além da privação da liberdade, são ainda penalizados com castigos corporais, exposição ao uso de drogas e ao contágio a várias enfermidades. Soma-se a isso o descumprimento dos dispositivos legais que regulamentam a privação de liberdade, no que diz respeito ao andamento do processo e também no que toca à questão da superlotação, da possibilidade de trabalho e da educação formal do detento. Essas privações desconstroem o valor da dignidade humana, assim como a possibilidade de reinserção social (Frinhani, 2004).

Deve-se ressaltar que, em comparação com a realidade dos presídios, as detentas citadas neste estudo possuem uma importante particularidade, devido ao "caráter provisório" que a instituição possui. Por ser uma delegacia, e não um presídio, é esperado que as detentas permaneçam pouco tempo até que sejam sentenciadas e transferidas para outras unidades. O que se observou, entretanto, é que algumas detentas já haviam sido 
sentenciadas e permaneceram na instituição por mais de três anos. Isso se deve, muitas vezes, ao fato de que a maioria das mulheres conta com defensor público e afirmam não se sentirem bem orientadas ou defendidas quanto aos seus processos ou seus trâmites. Acreditam que, se tivessem um advogado particular, poderiam ter mais chances de serem sentenciadas a uma pena mais leve ou de serem absolvidas pelos crimes.

Frinhani (2004) explica que o que acontece é que a maioria da população carcerária não tem condições de contratar um advogado, o que deixa as detentas sem conhecimento de sua situação jurídica e sem acesso aos benefícios previstos por lei.

No que diz respeito ao conhecimento sobre encarceramento, grande parte das informações que as mulheres deste estudo apresentaram estava restrito a algumas fontes provenientes da mídia televisiva, alguma experiência anterior com familiares ou amigos presos e, em alguns casos, através de passagens por alguma delegacia, quando foram presas em flagrante e levadas para prestar depoimento. O temor inicial, no entanto, foi reduzido quando as detentas efetivamente se inseriram no cárcere. Algumas mulheres relataram episódios de tentativa de extorsão, agressões físicas e verbais. As imagens inicialmente construídas são desfeitas quando ingressam no espaço prisional real. A diferença entre o que efetivamente encontram e o que esperavam encontrar possibilita uma primeira assimilação desse espaço. Assim, a construção da imagem que as detentas passam a fazer de si envolve os motivos que as levaram ao encarceramento, à percepção do espaço onde estão inseridas e das outras mulheres ali presentes.

Há relatos das dificuldades enfrentadas pelas detentas para se incluírem em determinados grupos, o que faz com que passem a diferenciar entre "elas" e "eu", ou entre "aquele grupo" e o "meu grupo". Atribuem às outras detentas comportamentos e valores que não reconhecem como seus. Ora se diferenciam pelos grupos das celas (ex. "a cela 8 é a pior", onde as pessoas são mais intolerantes e violentas), ora pela diferença de delitos cometidos. Souza (2004) discute a dinâmica social de exclusão/inclusão e violência presente em diversas sociedades. Afirma que "(...) podemos identificar tais mecanismos de diferenciação e categorização que, em última análise, permitem identificar o outro, o diferente, aquele que não pertence ao grupo" (p. 64).

Esses dados também vão ao encontro da discussão sobre processos de categorização social apontados por Joffe (1995) ao investigar as representações sociais sobre o surgimento da AIDS. Ainda que haja uma categorização social na qual bandido é considerado "tudo igual", no universo prisional, é construída uma categorização grupal própria em que os grupos se diferenciam entre si. O distanciamento do outro grupo protege o próprio grupo e a si mesmo, promovendo laços de solidariedade entre os membros do grupo e criando penalização para os diferentes. São freqüentes as queixas relacionadas com a bagunça, com a fofoca e com a deslealdade, em um processo de aproximação e diferenciação.

Embora a maioria das entrevistadas afirme ter bons relacionamentos entre si, reclamam por terem poucas ou nenhuma amizade. Relatam que as outras detentas são "falsas" e não merecem confiança. Em contrapartida, existem relatos que indicam comportamentos solidários entre as que pertencem ao mesmo grupo, tais como: partilha da comida recebida, produtos de higiene e roupas, acolhimento emocional para as que chegam, troca de favores e contratação de serviços que possam auxiliar a renda familiar.

Tais observações assemelham-se aos dados de Lemgruber (1999), ao tratar da solidariedade nas prisões. Segundo a mesma, a solidariedade nunca é total entre populações de presos, mas também não chega a deixar de existir. 
Outro dado significativo diz respeito às duas divisões básicas que foram apontadas pelas detentas: 1) divisão entre "presas flagradas" (detentas que ainda não foram condenadas) e as "presas sentenciadas" (detentas já condenadas), e 2) entre presas condenadas que trabalham e as que não trabalham.

As "presas flagradas" são apontadas como mais barulhentas, "folgadas, agitadas e nervosas". O espaço a elas destinado é sempre o pior dentro da cela, conforme já observado no trabalho de Bastos (1997). Já o espaço das "presas sentenciadas" é apontado como melhor, com mais conforto e mais calmo. A diferença entre os dois grupos está na perspectiva que elas controem sobre aquele espaço. Por um lado, até a sentença, as "presas flagradas" acreditam que poderão ser absolvidas, o que faz com que elas não se sintam parte do espaço. Por outro, a dúvida sobre qual será a condenação, o "tamanho" da mesma e a falta de informação sobre sua situação processual geram grande ansiedade. Observou-se que as "presas sentenciadas", por terem melhor previsão do tempo de permanência no espaço prisional, procuram transformar tal espaço em um ambiente personalizado.

A ociosidade é outro aspecto que provoca desgaste entre as detentas, por não possuírem atividade recreativa ou de trabalho. Em alguns casos, relataram que só saíam para o atendimento médico ou psicológico. Para muitas mulheres, a falta de liberdade para fazer o que desejam, na hora que desejam e a dificuldade de ficarem sozinhas, "sem ninguém por perto para perturbá-las", são algumas das principais limitações da coletividade forçada.

Em relação às estratégias utilizadas pelas detentas para "suportar" o encarceramento, observou-se: 1) realização de trabalho na limpeza (com a possibilidade de obterem a remição da pena); 2) atividades de artesanato;
3) o cuidado com própria aparência ou com o espaço da cela; 4) apego aos filhos e demais familiares e 5) participação no grupo de alfabetização ou grupos de oração organizados por entidades religiosas diversas. Os grupos de oração são bem recebidos pelas detentas; algumas participavam de vários grupos, independentemente da religião que os promovia, afirmando que o principal é "ouvir o que Deus diz". Tais atividades também são vistas como uma oportunidade de sair mais vezes de dentro das celas, e, em alguns casos, uma alternativa para ficar livre de medicamentos.

Também foi possível trabalhar com as expectativas das mulheres em relação ao futuro. Os projetos futuros apresentam um composto de medo, ansiedade e expectativas que coincidem com os projetos das detentas pesquisadas por Soares \& Ilgenfritz (2002). Geralmente, as detentas desejam recomeçar a vida e (re)iniciar atividades como cuidar dos filhos, estudar, afastar-se do mundo das drogas e trabalhar - mesmo sabendo que terão dificuldades em encontrar um trabalho por estarem com a "ficha suja" ou "marcadas" devido ao estigma de ex-presidiárias. As mulheres sabem que não é fácil o retorno à sociedade, e algumas detentas percebem que a vida na delegacia, apesar de apresentar muitas restrições e arbitrariedades, representa também uma proteção contra as incertezas da vida futura ou uma forma de proteção contra a vida que tinham antes de serem presas sobretudo para aquelas envolvidas com o crime organizado. Observa-se, em algumas mulheres, que o medo de serem soltas é tão grande quanto era o medo de serem presas.

Nesse sentido, o atendimento psicológico passa a ser um espaço valorizado pelas mulheres na medida em que oferece um espaço de reflexão e visibilidade social que, até o momento, não havia sido vivenciado por elas. Além disso, o atendimento, nesse contexto, contribui para proporcionar um 
momento de privacidade tão necessário ao enfrentamento da coletividade forçada, como mencionado acima.

\section{Maternidade e relações familiares}

Alterações nos lares são freqüentemente mencionadas pelas mulheres aprisionadas, dentre elas: 1) o aumento da responsabilidade dos filhos mais velhos, que passam a cuidar da casa e dos irmãos mais novos; 2) a preocupação com a entrada ou permanência no crime de filhos ou irmãos; 3 ) a quebra do vínculo com os familiares em função do sofrimento e constrangimento causados aos familiares. Cabe destacar a ênfase dada pelas detentas à relação com as mães e com os filhos, sempre citados com carinho, manifestando elas a preocupação de que eles possam perdoá-las.

Muitas mulheres relatam valorizar mais o convívio com a família depois de presas, apesar de a maioria mencionar que sempre teve um bom relacionamento familiar. Foram mencionadas, como dificuldades do cárcere, a preocupação e a saudade da família. Bastos (1997) afirma que os familiares se tornam uma ponte com o mundo externo, uma ligação delicada em função da distância, e frágil em função do não envolvimento direto com as questões cotidianas.

O contato com a família ocorre nos momentos de visita, que geralmente é esperado com ansiedade e com cuidados referentes à aparência pessoal e à arrumação do pátio. $\mathrm{O}$ cuidado com o ambiente também pode ser visto como um indicativo de que as mulheres cuidam de si e esperam que seus visitantes se sintam bem. Quando os familiares, principalmente mães e filhos, não comparecem às visitas, as presas buscam o atendimento ora ressentidas, ora preocupadas com as ausências. Algumas mulheres justificavam a ausência familiar pela dificuldade de deslocamento dos parentes, pelo constrangimento de passarem pela "revista" e pela tristeza de terem um familiar preso. A "revista" aos familiares é apontada por Soares \& Ilgenfritz (2002) como um procedimento "constrangedor", "humilhante" $\mathrm{e}$ "ineficiente", já que nem sempre consegue impedir a entrada de drogas, celulares e outros objetos ilícitos dentro do cárcere.

Nesse sentido, outro ponto importante é a percepção de que o universo prisional não se restringe ao confinamento ao qual estão submetidas. Inclui relações externas que as influenciam e afetam, fazendo com que mantenham preocupações com os acontecimentos externos e suas repercussões na vida de seus familiares. Essas preocupações mobilizam as mesmas a buscar estratégias de enfrentamento dessas questões, mesmo estando presas, visando a manter um lugar no mundo familiar e social.

\section{Vivências amorosas e relações de gênero}

A ausência masculina foi indicada pelas detentas como fator agravante para a permanência no cárcere. Apontam a falta de relacionamentos afetivos e sexuais com o sexo oposto, principalmente por não terem visitas íntimas, o que favorece envolvimentos afetivos/sexuais entre as detentas. A maioria das mulheres iniciou tais experiências durante o aprisionamento, o que gerava dúvida sobre a continuidade ou não dessa "escolha", embora percebam a importância dessas relações para o enfrentamento da condição carcerária, na medida em que oferecem e recebem proteção e cuidados. Existiam casos em que algumas detentas já possuíam tal orientação sexual antes de serem presas. Assis \& Constantino (2001) destacam que "o homossexualismo de internato" é uma construção institucional, comum em espaços de reclusão, servindo como estratégia de enfrentamento do cárcere no sentido da preservação dos afetos.
Muitas mulheres relatam valorizar mais o convívio com a familia depois de presas, apesar de a maioria mencionar que sempre teve umbom relacionamento familiar. Foram mencionadas, como dificuldades do cárcere, a preocupação e a saudade da família. Bastos (1997) afirma que os familiares se tornam uma ponte com o mundo externo, uma ligação delicada em função da distância, e frágil em função do não envolvimento direto com as questões cotidianas. 
Alguns relatos sinalizaram características de gênero, na vivência prisional feminina, no que diz respeito à relações afetivas maternais entre as presas, que envolveram cuidados, proteção, acolhimento e aconselhamento das mulheres mais velhas para as mais jovens.

\section{Reflexões finais}

Um trabalho que se propõe a lidar, ao mesmo tempo, com múltiplos aspectos de um fenômeno social não pode se encerrar sem que fique uma sensação de que mais poderia ter sido feito. Entretanto, entendemos e aceitamos que o próprio social e a rede de significados formada por ele comportam sempre outras possibilidades de abordagem e análise; assim, a completude só seria possível se todas essas fossem consideradas, tarefa obviamente do campo da impossibilidade. Dessa forma, trabalhar com um recorte do fenômeno só pode ser considerado válido se esse recorte e seu tratamento permitem que se veja um traço a partir do qual se pode intuir o restante.

Abordar o universo institucional de mulheres encarceradas possibilitou-nos, no nosso entender, observar como se constituem, no grupo de sujeitos por nós atendidos, os mecanismos que possibilitam a busca de alternativas frente a uma experiência de exclusão.

O que pudemos perceber, em muitos casos, é que a busca por reconhecimento, inclusão e visibilidade social desses sujeitos se faz, muitas vezes, pela afirmação de poder via criminalidade. Quando tratamos especificamente da questão do tráfico de drogas, delito muito incidente entre as mulheres entrevistadas por nós, concordamos com Tavares \& Menandro (2004) com a indicação que o tráfico de drogas produz a sensação do ganhar dinheiro fácil, da "autoridade de bandido" com poder absoluto sobre o outro, e, por fim, da não-subjugação às regras sociais, além de reafirmar um ideal de consumo e acesso a bem materiais tão difundido pelo modelo neoliberal.

Apesar dessa tentativa de inclusão via criminalidade, o que ocorre, muitas vezes, é o aprisionamento desses sujeitos, e, nesse aspecto, foi interessante notar que, apesar dos preceitos legais que destacam o caráter ressocializador como prioritário, o que a prisão consegue reproduzir é o modelo de exclusão e violência que já assinalava a vida dessas mulheres anteriormente, fomentando, assim, a assimilação de valores imersos na cultura prisional que não correspondem aos valores desejáveis para uma existência extramuros.

A ausência do Estado na proposição de estratégias eficazes que previnam a manifestação da violência e que também favoreçam a recuperação/ressocialização dos cidadãos em conflito com a lei mantém a desigualdade e a miséria, que, em conseqüência, reiniciam o ciclo de violência/ criminalidade/exclusão.

Tavares \& Menandro (2004) afirmam que as prisões brasileiras funcionam como mecanismo de oficialização da exclusão que já perpassa a vida dos detentos, não só tomando como referência a precariedade das condições proporcionadas pelo aprisionamento, mas também a precariedade das condições de vida desses sujeitos antes do encarceramento, em sua maioria, provenientes de grupos marcados pela exclusão. Questionam também as perspectivas de vida que essas pessoas podem vislumbrar ao saírem do sistema carcerário como ex-presidiários.

Não podemos deixar de mencionar que ocorre, também, uma articulação, no senso comum, entre a noção de direitos humanos e o privilégio de bandidos. Essa vinculação acaba por tornar a população contrária à defesa dos direitos humanos, uma vez vinculada aos presos. Esse tipo de postura acaba por dificultar qualquer possibilidade de implementação de 
projetos que atendam essa população, ou ainda, a implementação de políticas públicas que favoreçam a reinserção social dos egressos.

Assim, seria de fundamental importância agregar esforços, recursos e idéias para desenvolver atividades de extensão, ensino e pesquisa em frentes vinculadas ao campo da Psicologia social. Através de projetos desse tipo, pretende-se oferecer aos psicólogos em formação excelentes espaços de atuação, que favoreçam o aprendizado com seriedade ética e possibilitem a aquisição das competências exigidas para o desenvolvimento de atividades desse porte.

Sob esse ponto de vista, trabalhar com sujeitos encarcerados se torna um dos desafios para o avanço da Psicologia, à medida que tais atividades permitem a construção de reflexões e ações acerca da percepção sobre as diversas práticas institucionais, sociais e políticas que negligenciam as formas de construção de cidadania, visando a contribuir com subsídios que possam favorecer os programas de redução de violência e reinserção social das egressas do sistema prisional.

Por fim, admitimos, mais uma vez, os limites de nosso trabalho, muitas vezes decorrentes da própria situação estudada. Entretanto, consideramos também a importância do que foi aqui discutido, sua relevância para a investigação e o entendimento de questões que só podem ser validadas no cotidiano de cada sujeito e através da sua fala.

Marcela Ataide Guedes

Psicóloga, graduada pela Universidade Federal de Minas Gerais - UFMG. Pós-graduanda em Psicologia clínica - ênfase em Gestalt-terapia pela Faculdade de Estudos Administrativos - FEAD. Rua Timbiras, 1364 apto 703B - Funcionários - Belo Horizonte - MG. Cep: 30140-060 Tel: (031) 3234 4162. E-mail:marcela_guedes@yahoo.com.br

Recebido 16/01/06 Reformulado 17/10/06 Aprovado 09/11/06

ALMEIDA, R. de O. Mulheres que Matam: Universo Imaginário do Crime no Feminino. Rio de Janeiro: Relume Dumará, UFRJ, 2001, $672 p$.

ASSIS, S. G. \& CONSTANTINO P. Filhas do Mundo: Infração Juvenil no Rio de Janeiro. Rio de Janeiro: Fiocruz, 2001, 284p.

BARBANTI, L. F. \& CHALOM M. H. Um Serviço de Plantão Psicológico em Instituição Judiciária: Ilustração Prático-teórica. In: Morato, H. T. P. Aconselhamento Psicológico Centrado na Pessoa: Novos Desafios. São Paulo: Casa do Psicólogo, 1999, pp. 187-204.

BASTOS, M. Cárcere de Mulheres. Rio de Janeiro: Diadorim Editora Ltda, 1997.

BECKER, H. S. Métodos de Pesquisa em Ciências Sociais. $2^{\underline{a}}$ ed. São Paulo: Hucitec, 1994.

FRINHANI, F. M. D. Mulheres Aprisionadas: Representando o Universo Prisional. Dissertação de Mestrado em Psicologia. Universidade Federal do Espírito Santo, Vitória - ES, 2004, $146 f$.

JOFFE, H. "Eu não", "o meu Grupo não". Representações Sociais Transculturais da AIDS. In: Jovchelovitch, S. \& Guareschi, P. (orgs.) Textos em Representações Sociais. Petrópolis: Vozes, 1994, pp. 297-322.

LEMGRUBER, J. Cemitério dos Vivos: Análise Sociológica de uma Prisão de Mulheres. $2^{a}$ ed. Rio de Janeiro: Forense, 1999, 142 p.

MAHFOUD, M. A Vivência de um Desafio: Plantão Psicológico. In: Rosemberg, R. L. (org.). Aconselhamento Psicológico Centrado na Pessoa. São Paulo: EPU, 1987, pp.75-83.

MENANDRO, P. R. M. A Curva Generosa da Compreensão: Temas em Metodologia. In: Souza, L.; Freitas, M. F. Q.; Rodrigues, M. M. P. (orgs.) Psicologia: Reflexões (Im)Pertinentes. São Paulo: Casa do Psicólogo, 1998, pp. 397-417, 422 p.
MINAYO, M. C. S. O Desafio do Conhecimento. Pesquisa Qualitativa em Saúde. São Paulo- Rio de Janeiro: Hucitec-Abrasco, 1999, 269 p.

SOARES, B. M. \& ILGENFRITZ, I. Prisioneiras: Vida e Violência atrás das Grades. Rio de Janeiro: Garamond, 2002, 150p.

SOUZA, L. Processos de Categorização e Identidade: Solidariedade, Exclusão e Violência. In: Souza, L. \& Trindade, Z. (orgs.) Violência e Exclusão: Convivendo com Paradoxos. São Paulo: Casa do Psicólogo, 2004, pp.57-74.

TAVARES, G. M. \& MENANDRO, P. R. M. Atestado de Exclusão com Firma Reconhecida: o Sofrimento do Presidiário Brasileiro. Psicologia: Ciência e Profissão, 24 (2), pp. 86-99, 2004.

TRINDADE, Z. A. Concepções de Maternidade e Paternidade: o Convívio Atual com Fantasmas do Século XVIII. In: Souza, L. (org). Psicologia: Reflexões (Im)Pertinentes. São Paulo: Casa do Psicólogo, 1998, pp. 129-155.

Concepções Arcaicas de Maternidade e Paternidade e seus Reflexos na Prática Profissional. Interfaces, Salvador, 2 (1), pp. 33-40, 1999.

VELHO, V. Violência, Reciprocidade e Desigualdade: uma Perspectiva Antropológica. In: Velho, V. \& Alvito. M. (orgs.) Cidadania e Violência. Rio de Janeiro: Editora UFRJ: Editora FGV, 2000, pp. 11 -25 .

ZALUAR, A. A Globalização do Crime e os Limites da Explicação Local. In: Velho, V. \& Alvito. M. (orgs.) Cidadania e Violência. Rio de Janeiro: Editora UFRJ: Editora FGV, 2000, pp. 49-69. 